\title{
A Família nas Novas Parentalidades. Um Pensamento Rizomático
}

\author{
La Familia en las Nuevas Parentalidades. Un Pensar Rizomático
}

The Family in the new Parenting. A Rhizomatic Thinking

\section{Cecilia Marotta Mendez \\ ORCID: http://orcid.org/0000-0002-3544-3931 \\ Universidad de la República Oriental del Uruguay, Montevideo/Uruguai}

Declaração de Direito Autoral

A submissão de originais para este periódico implica na transferência, pelos autores, dos direitos de publicação impressa e digital. Os direitos autorais para os artigos publicados são do autor, com direitos do periódico sobre a primeira publicação. Os autores somente poderão utilizar os mesmos resultados em outras publicações indicando claramente este periódico como o meio da publicação original. Em virtude de sermos um periódico de acesso aberto, permite-se o uso gratuito dos artigos em aplicações educacionais e científicas desde que citada a fonte conforme a licença CC-BY da Creative Commons.

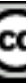

\section{(i)}

Creative Commons Atribuiç̃o 4.0 Internacional.

\section{Resumo}

Neste artigo, apresentamos alguns pontos sobre as implicações de trabalhar e pesquisar com famílias e parentalidades no atual contexto geopolítico. São reflexões do ensino universitário de uma Psicologia Social no Uruguai. Procuramos problematizar o que se entende por família e para isso tomamos algumas linhas de significado da palavra para focar a análise. Uma delas é pensar nela como uma instituição em seu jogo de conservação e mudança, baseada em contextos sóciohistóricos. Outra abordagem da análise é a articulação que ocorre na contemporaneidade entre a família e a nova parentalidade, entendendo o conceito de parentalidade como um analisador da época. Em seguida, nos referimos ao lugar que a família adquire nos discursos dos movimentos antigênero, que atacam os direitos conquistados e proclamam o retorno à família tradicional. Nesse sentido, nos perguntamos sobre as ameaças que surgem nas novas composições familiares e a produção de subjetividade alternativa à lógica capitalista. Como fechamento, propõe-se um pensamento rizomático que leva em conta a conexão entre família e política, bem como uma análise intersetorial das desigualdades presentes nas famílias. A intenção é aprofundar as conexões entre a construção do coletivo e o comum na nova parentalidade. Bem como o desafio ético-político das universidades públicas latino-americanas, de modo que eles são espaços de produção de pensamento livre e localizados nos debates atuais.

Palavras-chave: Famílias; Novas parentalidades, Rizoma.

\section{Resumen}

En este trabajo realizamos algunas puntualizaciones sobre las implicancias que tiene trabajar e investigar con familias y parentalidades en el contexto geopolítico actual. Son reflexiones a partir de la docencia universitaria de una Psicología Social en Uruguay. Procuramos problematizar qué se entiende por familia y con ese fin tomamos algunas líneas de significación del vocablo para enfocar el análisis. Una de ellas es pensarla como institución en su juego de conservación y cambio, en función de los contextos socio-históricos. Otro enfoque de análisis es la articulación que se produce en la contemporaneidad entre familia y nuevas parentalidades, entendiendo el concepto de parentalidad como un analizador de época. Seguidamente hacemos alusión al lugar que adquiere la familia en los discursos de los movimientos anti género, que arremeten contra los derechos 
conquistados y pregonan el regreso a la familia tradicional. En ese sentido nos preguntamos acerca de las amenazas que se plantean en las nuevas composiciones familiares y la producción de subjetividad alternativa a la lógica capitalística. Como cierre se propone un pensar rizomático, que tome en cuenta la conexión entre familia y política así como un análisis interseccional de las desigualdades presentes en las familias. Se deja planteada la intención de profundizar en las conexiones entre la construcción de lo colectivo y lo común en las nuevas parentalidades. Así como el desafío de carácter ético-político para las universidades públicas latinoamericanas, para que las mismas sean espacios de producción de pensamiento libre y situado en los debates actuales.

Palabras claves: Familias; Nuevas parentalidades; Rizoma.

\begin{abstract}
In this paper we perform some points about the implications of working and researching with families and parenting in the current geopolitical scene. They are reflections from the university teaching of a Social Psychology in Uruguay. We try to problematize what is meant by family and to that end we take some lines of meaning of the word to focus the analysis. One of them is to think of it as an institution in its game of conservation and change, based on socio-historical contexts. Another approach to analysis is the articulation that occurs in the contemporaneity between family and new parenting, understanding the concept of parenthood as an analyzer of time. Next, we refer to the place that the family acquires in the speeches of the anti-gender movements, which attack the rights conquered and proclaim the return to the traditional family. In that sense we ask ourselves about the threats that arise in the new family compositions and the production of alternative subjectivity to the capitalist logic. As a closure, a rhizomatic thinking is proposed that takes into account the connection between family and politics as well as an intersectional analysis of the inequalities present in families. The intention is to deepen the connections between the construction of the collective and the common in the new parenting. As well as the ethical-political challenge for Latin American public universities, so that they are spaces of free thought production and situated in current debates.
\end{abstract}

Keywords: Families; Parenting; Rizoma.

\section{Introducción}

Este trabajo pretende realizar algunas puntualizaciones acerca de las implicancias que tiene trabajar e investigar con familias y parentalidades en el contexto geopolítico actual. Se propone una elucidación del dispositivo teórico-metodológico del que somos parte como investigadores, y se asienta en un quehacer procedimental basado en el análisis de las implicaciones.

Son reflexiones desde la práctica de investigación, enseñanza y extensión en psicología social en la universidad pública de Uruguay, pero manteniendo la tensión con otros saberes transversales que toman la familia como campo de problemas. Son elaboraciones producidas en los intersticios
(Roussillon, 2002), en los pasillos (Fernández Christlieb, 2003) de las instituciones académicas y profesionales, a modo de agenciamientos colectivos de una práctica institucional compartida. Siguiendo a René Roussillon (2002) algo de "lo no mentalizado" en la estructura institucional

debe de encontrar un modo de existencia individual y grupal, que debe ser suficientemente protegido para no ser destruido, u obligado a un enquistamiento que haría difícil su elaboración ulterior, y destruiría su valor potencial, pero al mismo tiempo suficientemente expresado como para que siga siendo posible cierta "reanudación "oficial ulterior. (p. 190). 
En primer lugar presentamos algunas líneas de significación del vocablo familia, a partir de su procedencia etimológica y mostrando cómo su definición ha ido variando de acuerdo a procesos socio-históricos. Una de las líneas que orienta el análisis es pensar la familia como institución en su juego incesante de cambios y conservación. Además, interesa remarcar que las definiciones de familia no son fijas ni estables, sino que están asentadas en regímenes de verdad que privilegian un determinado orden político y sexual. En este sentido, han sido los movimientos feministas y de la diversidad sexual quienes han puesto en cuestión este orden, promoviendo una crítica al esencialismo de la familia y relaciones más igualitarias al interior de las mismas. Siguiendo con el análisis de las transformaciones en las familias, proponemos la articulación con el concepto de parentalidades, de más reciente aparición y que a nuestro juicio se erige en analizador de época. Por ese motivo hablaremos de familias y no de familia, y de un dispositivo de la parentalidad donde la institución se redefine. El segundo apartado ubica tal problematización en el actual contexto geopolítico regional, donde el embate conservador invoca a la familia tradicional nuclear y arremete contra la agenda de derechos y el enfoque de género. ¿Cuál es la amenaza que las nuevas composiciones de familias y parentalidades traen consigo? ¿Será que la familia en tanto formación subjetiva al verse conmovida por la subversión de un orden político y sexual burgués y patriarcal, se vuelve un riesgo para una sociedad tomada por una lógica capitalística que persigue una subjetividad dominante (Guattari y Rolnik, 2006)?

Como cierre del ensayo se deja planteada la invitación a un pensar rizomático sobre familias y parentalidades, que permita conocer y comprender sus cambios. Por otra parte, se esboza la intención de profundizar en las relaciones entre familias, nuevas parentalidades y sus conexiones con la construcción de lo colectivo y lo común, como proyecto político alternativo en el actual contexto geopolítico planetario. La segunda y última constatación es el desafío ético-político al que nos vemos enfrentados los investigadores de las universidades públicas, para que las mismas sean espacios de producción de pensamiento libre y situado en los debates actuales.

\section{1. - Familias y nuevas parentalidades Familia: ¿que viene siendo?}

El término familia proviene del latín y deriva de la palabra "famulus" que se traduce como sirviente o esclavo. En ese sentido era equivalente a patrimonio e incluía no solo a los parientes (mujer, hijos) sino a los esclavos o grupo de esclavos que residían en la misma casa y estaban subordinados al pater familias. Estas procedencias etimológicas permiten ubicar el escenario de producción del vocablo para nombrar una situación determinada, así como enfatizar líneas de sentidos y significaciones que se conectan con los debates actuales en torno al tema. Una de las líneas de significación remite a la Antigua Roma, donde el poder se concentraba en la figura del hombre, blanco y heterosexual. Bajo este orden político, quedaban la mujer, los hijos y los esclavos subyugados ante el poder del mismo. Roudinesco (2003) refiere que entre fines del siglo XVIII y mediados del XX se impone la "familia moderna" donde se incluye la afectividad para la elección conyugal, se sanciona el matrimonio y la división del trabajo entre ambos cónyuges. En este período interviene el Estado como formador del hijo en tanto ciudadano. Desde el Río de la Plata la argentina Ana María Fernández (1992) señala cómo la "grupalización" de la familia extensa en este período supuso no sólo la reducción en el número de personas adscriptas a la misma, sino que generó nuevos anudamientos subjetivos entre sus miembros. Siguiendo los estudios feministas de Silvia Federici (2018) en sus críticas al marxismo, este proceso de consolidación de la familia nuclear es un estadio de las relaciones capitalistas. La organización de la familia nuclear estableció la base para la producción capitalista, dice la 
filósofa, invisibilizando el trabajo de la mujer como productora de la fuerza de trabajo.

Con la postmodernidad este orden político y sexual se ve conmocionado, poniéndose en cuestión los presupuestos que fundaron un modelo, a saber: la unión conyugal y la institución del matrimonio como su base y fundamento, - la pareja heterosexual monogámica, -la asociación entre pareja conyugal y parental, .- la biparentalidad y el ejercicio de las funciones parentales de acuerdo a los roles prescriptos por el género, la filiación fundada en el vínculo biológico, la subordinación de los hijos a los padres. La crítica ha tenido en la primer trinchera al movimiento feminista que denuncia los aspectos invisibilizados de la reproducción social que propiciaron un "sujeto femenino" bajo la égida y poder masculino (Gutierrez, 2015). Es decir, que así planteada la familia se erige como dispositivo de sujeción de los cuerpos femeninos en relaciones de desigualdad.

Sin embargo, las décadas de los años sesenta y setenta del siglo $\mathrm{XX}$ han sido pródigos en impulsar cambios revolucionarios en la vida privada y en las formas de producir subjetividad, mostrando que no existe un único modelo de familia sino modos diversos y singulares de experimentar la familia. En la actualidad hay suficiente evidencia que muestra la diversidad de arreglos familiares como la característica principal de las formas de vida familiar en el siglo XXI.

Se vuelve necesario cuestionarnos en qué familia estamos pensando, practicando, de qué estamos hablando cuando intervenimos e investigamos con familias, sobre el entendido que nuestras acciones construyen realidad social. En este ensayo subrayamos un modo de pensar la familia como institución, en su movimiento incesante de lo instituido y lo instituyente. Desde la psicología social en Uruguay, el psicólogo Gabriel Eira (2002) distingue un nivel abstracto al entenderla como institución y otro nivel empírico donde se ubica al grupo humano. Dice Eira (2002): "La Familia es menos un objeto discreto discriminable que un complejo de fuerzas en permanente proceso de transformación. Visto así, la familia no cambia sino que es el cambio lo que la define como institución"(Eira, 2002, p.74), y la pregunta a formularse, más que la pregunta esencialista acerca de qué es una familia, debería ser ¿qué viene siendo la familia? Al igual que el resto de las instituciones de la modernidad, la familia va dejando de ser un espacio cerrado para volverse "universos abiertos, superpuestos e interrelacionados" (Eira, 2002, p.79). Desde esta perspectiva, la familia como institución es un terreno propicio para estudiar las transformaciones micropolíticas en curso, en las formaciones de sexo y género. En el entendido que son las instituciones en su juego de fuerzas de conservación y cambio, de luchas de poderes, en la dinámica de la cotidianeidad de los intercambios, las que van produciendo subjetividades nuevas.

\section{2.- Familias y nuevas parentalidades El dispositivo de la parentalidad}

El uso del concepto de parentalidad o parentalidades es más reciente que el de familias, impregnando el discurso de profesionales, agendas de política pública y debates académicos en Uruguay y otros países de la región. Haremos referencia al término parentalidad cuyo uso desde el sentido común se realiza como sinónimo de paternidad, o como sufijo o prefijo para nombrar la monoparentalidad, la homoparentalidad, entre otros. Aquí se toma en su calidad de sustantivo, y se entiende su aparición como un analizador de época, en tanto el mismo abre visibilidad sobre un aspecto central que hace al cuidado y a la relación entre las generaciones y el género en las familias. Se entiende la parentalidad como el ejercicio de las tareas relacionadas con la crianza, cuidados y educación de los hijos, las cuales estarían tradicionalmente asignadas a los padres biológicos y/o legales. $\mathrm{Su}$ enunciación "nombra y renombra antiguas y nuevas formas de lazo entre generaciones, otorgando sentido y direccionalidad a las intervenciones en lo social" (Santos, Di Fabio, Marotta, \& Pierri, 
2018, p 78). Es un concepto que aparece intrínsecamente conectado con la noción de cuidados hacia los niños, niñas y adolescentes y con el sostenimiento de la vida. Decíamos en el apartado anterior, que a partir de la década de los sesenta hay una mayor visibilidad $y$ crítica acerca del lugar de la mujer en las familias, transformándose asimismo las formas de subjetivación femenina. Esto se materializa en la desnaturalización de la función maternal, en el control sobre la natalidad y en el alto número de divorcios que ponen en cuestión la institución del matrimonio. Con estos movimientos se produce una crítica a la familia burguesa y patriarcal, transformándose asimismo el lugar de la niñez y las formas de concebir al sujetoniño, quien pasa a ser considerado sujeto de derecho.

La aparición del término parentalidad podría entenderse como un movimiento solidario con este nuevo status jurídico que adquiere el niño, consagrándose el derecho a vivir en familia. Pero no solo eso, también como un cambio en las prácticas de cuidado por parte de mujeres y hombres adultos hacia los niños, que cuestiona la propia institución familiar moderna. Al decir de Claude Martin (2003) hablar de parentalidades es un recurso de nominación para ir más allá del modelo original basado en el parentesco, mostrando que hay otras personas que pueden jugar un rol parental sostenido, que no tienen un status legal y tampoco vínculo de filiación biológica. Observamos que en las distintas configuraciones familiares presentes en la actualidad, la parentalidad se dispone a modo de red donde confluyen no sólo figuras ligadas por vínculo biológico sino por los afectos y la corresidencia. El ejercicio de las funciones parentales de acuerdo a los roles prescriptos por el género se ven alterados y emergen nuevos modos de crianza. Asimismo están presentes otros actores co-responsables en el cuidado como ser el Estado a través de sus planes y programas de asistencia, el mercado a través de su oferta variada, e incipientemente otras comunidades de cuidado de donde se juega la dimensión de lo colectivo (Vega,
Martine, \& Paredes, 2018). Existen otros espacios sociales como ser los grupos de pares, las tecnologías de comunicación, el lugar de los especialistas, entre otros. Todo lo cual configura un escenario donde se ve descentrado el papel privilegiado de las familias en la parentalización. La institución familia es pues capturada en un dispositivo de parentalidades donde coexisten prácticas discursivas y no-discursivas que reconfiguran la naturaleza de la propia institución.

Sin embargo, aún persiste el discurso que pregona un tipo de familia: la familia nuclear como el contexto ideal para el desarrollo saludable de niños y niñas. Sobre esa base se montan intervenciones que ven a las familias monoparentales como incompletas, o que encuentran riesgos en las parentalidades gays o lesbianas, o incluso en el levantamiento de los estereotipos de maternidad y paternidad ligados a las identidades sexuales.

\section{2. - El embate conservador sobre las familias}

Uno de los énfasis de los movimientos conservadores en la región es la defensa de la familia tradicional, oponiéndose férreamente a los logros en materia de derechos sexuales y reproductivos, así como al enfoque de género en el tratamiento de las relaciones sociales que se reproducen al interior de las familias.

Uruguay es un país laico que ocupa un lugar destacado a nivel continental y mundial por sus logros en materia de derechos, sin embargo el escenario socio-político actual es de fuertes tensiones y confrontación. A saber, la promulgación de la ley de unión concubinaria (Ley No. 18.246/2007), la ley de interrupción voluntaria del embarazo (Ley No. 18987/2012), la ley de matrimonio igualitario (Ley No. 19.076/2013) y la recientemente aprobada ley integral para personas Trans (Ley No. 19684/2018) provocan controversias y debates públicos. Al igual que en otros países de la región, grupos conservadores arremeten contra las agendas de derechos conquistados. Aparecen en la escena geopolítica con un 
discurso de odio y virulencia hacia los temas vinculados a sexualidad y género y al decir de Correa (2018) movilizan imaginarios simplistas que construyen como enemigos a las feministas, a los gays, a ciertos académicos y artistas, a los cuerpos trans. En este escenario dicotómico se elude debatir acerca de las desigualdades de clase que persisten y se agudizan, así como las de raza, género y generaciones entre otras (Correa, 2018).

El espacio familiar, como veníamos desarrollando en el apartado anterior, se transforma de acuerdo a variables históricas, sociales y políticas. En este sentido y frente a la virulencia que adquiere la prédica de odio de los movimientos antiderechos, la pregunta que surge es dónde está el peligro en la materialización del ejercicio de derechos por parte de hombres, mujeres y niños que han sido históricamente excluidos. ¿Será que la familia como formación subjetiva al verse conmovida por la subversión de un orden político y sexual burgués y patriarcal se vuelve un riesgo para una sociedad tomada por una lógica capitalística que persigue una subjetividad dominante (Guattari y Rolnik, 2006)?

\section{¿Qué subjetividad se produce en estas nuevas composiciones de familias $\mathrm{y}$ parentalidades contemporáneas? ¿Cómo se conecta la misma con nuevos horizontes políticos alternativos al capitalismo?} Parafraseando a Guattari (1998), la familia como equipamiento colectivo genera territorios existenciales para la producción de subjetividad de hombres y mujeres, de niños, niñas y adolescentes. Si dejamos de buscar la esencia de la familia y atendemos a las nuevas composiciones que existen, veremos cómo estas nuevas parentalidades se disponen como máquinas subjetivas. Las mujeres, otrora relegadas al ámbito doméstico, a la crianza de los hijos y la atención a los hombres, ahora se vuelcan al ámbito de lo público. Por otra parte, un enfoque de generaciones permite visualizar cómo también se ve cuestionada la perspectiva adultocéntrica. Duschatzky y Corea (2006) advierten cómo en las sociedades occidentales modernas, la familia ofició como eslabón para el proceso de filiación y construcción de la cadena intergeneracional. La familia ofrecía a los sujetos un lugar en la genealogía de sostén y referencia, cualidades que se ponen hoy en cuestión. Para el caso de la familia nuclear aluden a una organización paterno-filial asentada en la sociedad burguesa que debía producir futuros ciudadanos. La caída del Estado-nación, la destitución de la ley como organizador simbólico tiene efecto de vacío sobre las relaciones familiares y sus referencias ancladas en jerarquías simbólicas. Es interesante los modos de vinculación familiar que encuentran estas autoras: la desubjetivación, la resistencia o la invención. La primera de estas prácticas se caracteriza por la no existencia de lugares discriminados en las familias donde recaería la autoridad, la protección y el cuidado: son "modos desubjetivantes de habitar los vínculos familiares o, lo que es lo mismo, un no poder hacer casi nada con la situación" (Duschatzky \& Corea, 2006, p.72) en otro sentido operarían la resistencia y la invención. La primera de estas refiere a una defensa que operaría en las familias ubicando el peligro en el afuera y retardando la salida de la familia como lugar seguro y de protección. La invención es la operatoria de habitar las situaciones con recursos nuevos ajustados a lo nuevo. Si bien las autoras aluden a los modos de vinculación a la interna de los grupos familiares, remarcamos que ninguna de estas opciones refiere únicamente a procesos individuales. $\mathrm{La}$ dimensión subjetiva a la que hacemos referencia no remite a un sujeto individual sino a un proceso colectivo.

En las intervenciones que realizamos en el campo de familias y parentalidades, nos interesa abordar la dimensión de lo subjetivo que remite a lo social, una dimensión que emerge en los procesos colectivos. Desde esta perspectiva, lo subjetivo será un "pliegue del afuera en el sujeto" (Deleuze, 2018), donde los sujetos-familias no están ni afuera ni adentro. Lo subjetivo está en el pliegue a modo de movimiento reflexivo desde el propio mundo, que produce un sujeto-familia situado en un determinado tiempo histórico. Estas nuevas 
composiciones de familia producen nuevas vías de la subjetividad y es allí donde la invención nos muestra cómo se habitan las nuevas situaciones.

\section{3. - Pensar rizomáticamente la familia}

Dejamos planteada una propuesta que hace al fundamento epistémico sobre cómo pensar los cambios y las transformaciones en las familias, así como las intervenciones en ese campo. Para esto haremos referencia a la imagen de pensamiento del rizoma introducida por Deleuze y Guattari (2004) en Mil Mesetas. Estos autores arremeten críticamente a las formas del pensamiento clásico y moderno que grafican en la imagen del árbol, como posición hegemónica en la ciencia. La misma inscribe la realidad en un apriori significante, donde la razón lógica sería la clave para la comprensión y la significación. Desde esta perspectivaárbol, habría una representación previa que ordena y pre- determina las formas de significar la realidad: la imagen del libro-árbol como imitación del mundo. Un pensar rizomático es el despliegue de un modo de pensamiento que se contrapone a la lógica binaria o a un pensamiento por representación, donde los fenómenos se ajusten en teorías y /ó formas predeterminadas de interpretar el mundo. Un ejemplo de esto es presentar el plano de conexión entre familia y política en la actualidad, tradicionalmente confinada la primera al ámbito de la vida privada y la segunda al ámbito público. Sin embargo hay una naturaleza recíproca entre familia $\mathrm{y}$ política así como entre género y política, como lo ha desarrollado Joan Scott (1996). Parafraseando a la historiadora, el género es una forma primaria de relaciones significantes de poder, y desde este enfoque es una clave para pensar cuestiones de familias. Cómo veíamos en el apartado anterior, las formas de codificación política del campo de problemas sobre familia responden a una micropolítica de la familia nuclear heterosexual. Los significantes tradicionales codificaron el mundo a partir de axiomas normatizadores $\mathrm{y}$ normalizadores de un orden político (la pareja heterosexual monogámica, la filiación dada por el componente biológico, entre otros) centrado en la figura del poder masculino. Otro ejemplo para pensar rizomáticamente la familia es considerar el género como un marcador de la desigualdad existente, pero no en modo esencialista sino en conexión con otras desigualdades. A diferencia del árbol, pensar familia como rizoma es adentrarnos en la conexión de puntos que se conectan e interconectan, siendo además eslabones semióticos de distinto orden

En un rizoma, por el contrario, cada rasgo no remite necesariamente a um rasgo lingüístico: eslabones semióticos de cualquier naturaleza se conectan en él con formas de codificación muy diversas, eslabones biológicos, políticos, eco- nómicos, etc..., poniendo en juego no sólo regímenes de signos distintos, sino también estatutos de estados de cosas. En efecto, los agenciamientos colectivos de enunciación funcionan directamente en los agenciamientos maquínicos, y no se puede establecer un corte radical entre los regímenes de signos y sus objetos (Deleuze, Guattari, 2004, pp. 13).

Si bien las construcciones disciplinares territorializan unos saberes acerca de las familias (como por ejemplo el psicoanálisis, antropología, la sociología) y gran parte del movimiento feminista ubica la desigualdad con preeminencia en el género, otras líneas de fuga dentro del propio movimiento desterritorializan las interpretaciones.

Así, a menudo, uno se verá obligado a caer en puntos muertos, a pasar por poderes significantes y afecciones subjetivas, a apoyarse en formaciones edípicas, paranoicas, o todavía peores, como territorialidades rígidas que hacen posibles otras operaciones transformacionales. Hasta es muy posible que el psicoanálisis sirva, muy a pesar suyo, claro está, de punto de apoyo. En otros casos, por el contrario, habrá que apoyarse 
directamente en una línea de fuga que permite fragmentar los estratos, romper las raíces y efectuar nuevas conexiones." (Deleuze \& Guattari, 2004, p. 20).

Hay un sinnúmero de experiencias performativas en las familias dadas por la clase social, la raza, las generaciones, entre otros ejes de la discriminación que modulan subjetivamente las existencias. Un pensamiento rizomático se acerca al enfoque interseccional ( $\mathrm{La}$ Barbera, 2016) en el tratamiento de las desigualdades, donde para cada situación deberá atenderse al modo en que actúan como multiplicidad que se constituyen unas a otras simultáneamente. La puesta en cuestión que los nuevos arreglos familiares traen consigo dejan en evidencia que lo familiar se juega en el plano de la inmanencia y que el "objeto" familia no existe apriori sino en la co-emergencia del acto de investigar y/ó intervenir con familias.

\section{A modo de cierre: por suerte existen los pasillos}

Dice Fernández Christlieb (2003) en su psicología estética de la situación social, por suerte existen los pasillos.... Cuando plantea la imposibilidad de disciplinarse de la psicología social, criticando fuertemente a una psicología social más preocupada por su institucionalización académica que por la creación de conocimientos tentativos, provisorios para conocer la realidad social. Los pasillos como espacios de producción, que no deben confundirse con las oficinas, acota. El mejicano apela a una psicología social como un heurístico, retomando el origen griego de la palabra que significa encuentro. Aludiendo al encuentro como una forma de buscar

$y$, en efecto, se refiere al encuentro de una zona, u objeto, o idea, que no se sabe si existe (o se sabe que no existe) pero que permite ponerse a buscarla, a escudriñarla, y con eso, terminar por inventar lo que no existía, que no es lo que se buscaba ni lo que no se buscaba, sino algo tercero. (Fernández Christlieb, 2019, p.18).

Decíamos al comienzo que el ensayo toma la perspectiva de la psicología social junto a otros saberes transversales acerca de las familias y las parentalidades. Son reflexiones producidas en los intersticios de la institución universitaria que miran rizomáticamente a la familia como institución y como grupo humano donde se tejen formas de vida alternativas en un mundo de producción capitalística, al decir de Guattari y Roslnik (2006).

Para finalizar hay dos aspectos que queremos enfatizar para futuras elaboraciones: la primera de ellas tiene que ver con profundizar en las conexiones entre familias, nuevas parentalidades y la construcción de lo colectivo y lo común en el actual contexto geopolítico, como proyecto político alternativo a la subjetividad dominante. La segunda y última constatación es el desafío ético-político al que nos vemos enfrentados los investigadores de las universidades públicas, para que estas sean espacios de producción de pensamiento libre y situado en los debates actuales.

\section{Referências}

Correa, S. (2018). Ideología de Género: rastreando sus orígenes y significados en la política de género actual. [SPW, fórum global]. Recuperado de:

https://sxpolitics.org/es/ideologia-degenero-rastreando-sus-origenes-ysignificados-en-la-politica-de-generoactual $/ 3858$
Santos, N., Di Fabio, C., Marotta, A. C., Pierri, L. (2018). Parentalidades en acción. ¿Familias en cuestión? Una aproximación a las encrucijadas de la intervención. Revista Fronteras, 11, 77-87. Recuperado de https://www.colibri.udelar.edu.uy/jspui/han $\underline{\text { dle/20.500.12008/19999 }}$ 
Deleuze, G. (2018). La Subjetivación: Curso sobre Foucault, tomo III. Buenos Aires, Argentina: Cactus

Deleuze, G., \& Guattari, F. (2004). Introducción. In G. Deleuze, \& F. Guattari, Mil Mesetas: Capitalismo y esquizofrenia (pp. 9-21). Valencia, España: Pre-textos.

Duschatzky, S. \& Corea, C. (2006). Chicos en band: Los caminos de la subjetividad en el declive de las instituciones. Buenos Aires, Argentina: Paidós

Eira, G. (2002). Familia y grupo familiar. In J. Fernández, \& A. Protesoni (Comp.), Psicología Social: Subjetividad y Procesos Sociales (pp.71-80). Montevideo, Uruguay: Ediciones Trapiche

Federici, S. (2018). El patriarcado del salario: Críticas feministas al marxismo. Buenos Aires, Argentina: Tinta y limón

Fernández, A. M. (1992). El campo grupal. Buenos Aires, Argentina: Nueva Visión

Fernández Christlieb, Pablo (2019). Todos los psicólogos sociales: recapitulación de cuatro o cinco décadas. Athenea Digital, 19(1), e2444. doi:

10.5565/rev/athenea.2444

Fernández Christlieb, P. (2003). Political psychology as social aesthetics. Revista Interamericana de Psicologia/Interamerican Journal of Psychology, 37(2), 253-266. doi: 10.30849/rip/ijp.v37i2.824

Guattari, F. (1998). I. Conferencias: La producción de subjetividad del capitalismo mundial integrado. In F. Guattari, In $E l$ Devenir de la Subietividad: Conferencias, Entrevistas, Dialogos (Chile, 1991) (pp. 25-40). Santiago de Chile, Chile: Dolmen Ediciones

Guattari, F., \& Rolnik, S. (2006). Micropolítica: Cartografias do desejo. Petrópolis, Brasil: Vozes.

Gutierrez, R. (2015). Desandar el labirinto: Introspección en la feminidad contemporánea. Buenos Aires, Argentina: Tinta y limón.

La Barbera, M. C. (2016). Interseccionalidad, un "concepto viajero": orígenes, desarrollo e implementación en la Unión Europea.

Interdisciplina, 4(8), 105-122. doi: 10.22201/ceiich.24485705e.2016.8.54971

Martin, C. (2003). La parentalite en question: Perspectives sociologiques. Rapport au Haut conseil de la population et de la famille. Recuperado de:

http://www.ladocumentationfrancaise.fr/rap ports-publics/034000552/index.shtml

Scott, J. (1996). El género, una categoría útil para el análisis histórico. In M. Lamas (comp.), El género: la construcción cultural de la diferencia sexual (pp. 265302). México: UNAM.

Roudinesco, E. (2003). La familia en desorden. Argentina: Fondo de Cultura Económica.

Roussillon, R. (2002). Espacios y prácticas institucionales: La liberación y el intersticio.

In R. Kaes, J. Bleger, E. Enriquez, F. Fornari, F. Fustier, R. Rousillon, J. P. Vidal, La institución y las instituciones: Estudios psicoanalíticos (pp. 188-212). Argentina: Paidós.

Uruguay. (2007). Ley $n^{o} 18.246$, Union Concubinaria. Recuperado de https://legislativo.parlamento.gub.uy/tempo rales/leytemp5391125.htm

Uruguay. (2012). Ley $n^{\circ}$ 18987, Interrupción voluntaria del embarazo. Recuperado de https://www.impo.com.uy/bases/leyes/1898 7-2012/3

Uruguay. (2013). Ley $n^{\circ}$ 19.075, Matrimonio Igualitario. Recuperado de https://legislativo.parlamento.gub.uy/tempo rales/leytemp3233547.htm

Uruguay. (2018). Ley $n^{\circ}$ 19684, Ley integral para personas trans. Recuperado de http://www.impo.com.uy/bases/leyes/19684 $\underline{-2018}$

Vega, C., Martinez, R., \& Paredes, M. (2018). Experiencias y vínculos cooperativos en el sostenimiento de la vida en América Latina y el sur de Europa. Madrid, España: Traficantes de sueños 


\section{Dados sobre a autora:}

- Cecilia Marotta Mendez: Profesora Adjunta del Instituto de Psicologia Social. Facultad de Psicología - UDELAR. Magister en Atencion a la Salud en el Primer Nivel. Facutad de Enfermería - UDELAR. Doctoranda del Programa de Doctorado en Psicologia. Facultad de Psicología - UDELAR. Becaria de Posgrado de la Agencia Nacional de Investigacion e Innovación (ANII). 